\title{
Timelines as a tool for learning about space weather storms
}

\author{
Delores J. Knipp ${ }^{1,2, *}$, Valerie Bernstein ${ }^{1}$, Kaiya Wahl $^{3}$, and Hisashi Hayakawa ${ }^{4,5,6}$ \\ ${ }^{1}$ Smead Aerospace Engineering Sciences Department, University of Colorado Boulder (CU), Boulder, Colorado 80309, USA \\ ${ }^{2}$ CU Space Weather Technology Research and Education Center, Boulder, Colorado 80309, USA \\ ${ }^{3}$ Creative Technology and Design Engineering Department, University of Colorado Boulder, Boulder, Colorado 80309, USA \\ ${ }_{5}^{4}$ Institute for Space-Earth Environmental Research, Nagoya University, Nagoya 4648601, Japan \\ ${ }^{5}$ Institute for Advanced Researches, Nagoya University, Nagoya 4648601, Japan \\ ${ }^{6}$ UK Solar System Data Centre, Space Physics and Operations Division, RAL Space, Science and Technology Facilities Council, \\ Rutherford Appleton Laboratory, Harwell Oxford, Didcot, Oxfordshire, OX11 0QX, UK
}

Received 20 December 2020 / Accepted 8 March 2021

\begin{abstract}
Space weather storms typically have solar, interplanetary, geophysical and societal-effect components that overlap in time, making it hard for students and novices to determine cause-and-effect relationships and relative timing. To address this issue, we use timelines to provide context for space weather storms of different intensities. First, we present a timeline and tabular description for the great auroral storms of the last 500 years as an example for space climate. The graphical summary for these 14 events suggests that they occur about every 40-60 years, although the distribution of such events is far from even. One outstanding event in 1770 may qualify as a one-in-500-year auroral event, based on duration. Additionally, we present two examples that describe space weather storms using solar, geospace and effects categories. The first of these is for the prolonged storm sequence of late January 1938 that produced low-latitude auroras and space weather impacts on mature technology (telegraphs) and on high frequency radio communication for aviation, which was a developing technology. To illustrate storm effects in the space-age, we produce a detailed timeline for the strong December 2006 geomagnetic storm that impacted numerous space-based technologies for monitoring space weather and for communication and navigation. During this event there were numerous navigations system disturbances and hardware disruptions. We adopt terminology developed in many previous space weather studies and blend it with historical accounts to create graphical timelines to help organize and disentangle the events presented herein.
\end{abstract}

Keywords: space weather / great auroral storms / intense magnetic storms / visualization / storm effects

\section{Introduction}

Almost all space weather storms have a solar source in a solar magnetic active region (AR) or at the interface of closed/open magnetic regions that extend into space. Eruptions from these regions can be electromagnetic (solar flares; radio bursts) and/or in magnetic bursts (interplanetary coronal mass ejections - ICMEs) or intervals of high-speed solar wind streams preceded by stream interaction regions. Solar flares produce immediate sudden ionospheric disturbances on Earth's dayside. Flares and ICMEs can create conditions for acceleration of charged particles to very high energies, resulting in solar energetic particle (SEP) events. High-speed streams and ICMEs interact with the geomagnetic field to produce magnetic storms, auroral storms and ionosphere-thermosphere storms. Technology experiences the brunt of these storms in different ways as we illustrate later in the paper. We note that terms like ICME and SEP event were not used in early descriptions of several events we discuss here, nonetheless the terms convey our current understanding of historical events.

The timing, terminology, intensity and event-sequencing for space weather can be confusing to those new to the discipline. Descriptors like "strong," "severe" and "super/extreme/great" storms are often used by agencies, scientists and the media in different ways. With reference to auroral storms, we use "great" to mean a storm or disturbance that occurs a few times in a century (others have used "great" more broadly to mean approximately once-a-decade). There is no single scale for quantifying

*Corresponding author: delores.knipp@colorado. edu 
such storms. We provide: 1) ideas for envisioning and teaching about space weather and conveying it importance to broader society and 2) insights into space weather storm intensity. The latter is a very fluid concept because new technologies become susceptible to space weather in different and sometimes unanticipated ways.

Section 2 of this paper tabulates great aurora of the past. By consolidating available worldwide literature records from the past 500 years we show that great low-latitude aurora those with aurora visible to the unaided-eye equatorward of $30^{\circ}$ magnetic latitude (e.g., Cliver \& Svalgaard, 2004), occur roughly every $40-60$ years during the past 500 years. We suggest an event in 1770 as a candidate for a one-in-500-year auroral storm, based on duration. Section 3 provides a visual framework for one of these storms: The January 1938 sequence is an exemplar of a great storm event (as reported in Hayakawa et al., 2021a) in an era when telegraph communications were being replaced by radio communications to support the developing aviation community. Section 4 provides details of a storm in December 2006 that, while not a great auroral storm, offers insight into effects that might be expected from a strong magnetic storm in upcoming solar cycles, given humanity's reliance on space. This mid-latitude auroral storm in 2006 had broad effects on space-based technologies including global navigation services and at the International Space Station (ISS). Section 5 provides a brief discussion and additional commentary on educational use of timelines.

\section{0 years of great auroral storms visible at or below $30^{\circ}$ magnetic latitude}

Although a close association between auroral and magnetic storms was reported in the 1740s (Hiorter, 1747), routine magnetometer measurements started only in the mid-19th century. Thus, we have less than a 200-year record of geomagnetic storm behavior. A much longer but intermittent record of auroras reveals anecdotes and observations going back centuries. The reference lists in Willis \& Stephenson (2000), Stephenson et al. (2004), Vaquero \& Vázquez (2009) and Maden (2020) provide starting points for further reading on this subject. In this space-climatology example, we combined archival and worldwide-web literature searches with timeline software to characterize the great low-latitude auroral events of the past 500 years. Our initial search for great auroral storms focused on the International Geophysical Year (IGY) list championed by Baron Marcel Nicolet (Nicolet, 1959) and then on lists in Vallance Jones (1992) and Cliver \& Svalgaard (2004).

Sixty-five years ago, in preparation for the IGY, leaders of the Scientific Committee of the IGY (CSAGI - French acronym) at the Western Hemisphere Regional Conference in Rio de Janeiro, issued a challenge: "... that in each of the countries of the western hemisphere the records will be searched for great auroras of the past." (Nicolet, 1959, p. 517). The meeting document suggested that: "Information should be available from journals and newspapers for the following periods which cover some of the greatest magnetic storms and auroral displays of the past 100 years: 1 September 1859, 4 February 1872, 17 and 22 November 1882, 31 October 1903, 25 September 1909, 13 May 1921, 25 January 1938, 16
April 1938, 24 March 1940, 1 March 1941 and 18 September 1941, 28 March 1946 and 21 September 1946." Five of these storms appear in our discussion of great low-latitude aurora. Two storms from the Vallance Jones (1992) and Cliver \& Svalgaard (2004) lists, and seven storms from 1520-1870 have been added as a result of literature searches. As we discuss later, a number of the remaining storms in the CSAGI list were longlasting, mid-latitude auroral storms that produced very bright auroras, strong geomagnetic perturbations, and/or had notable technology impacts.

Figure 1 shows a timeline of 14 distinct events with auroras visible at or equatorward of $30^{\circ}$ magnetic latitude (MLAT) during that last 500 years. The choice of $30^{\circ}$ MLAT visibility is an easily applied criterion used by Cliver \& Svalgaard (2004) that requires only archived reports from human-eye sensors. This simple criterion allows us to capture early storms archived in the literature. The same criterion can be applied to future events. For context in Figure 1, we show periods of low sunspot activity (grand/secular minima; see Usoskin et al., 2007, 2011; Silverman \& Hayakawa, 2021) when the probability of strong Sun-geospace interactions is reduced. Figure 1 gives a representative, but probably incomplete sample of great auroral events in the last 500 years. Some events may have been lost or not recorded and cloudiness may have prevented observations of some storms that should be included. Others may yet be found. At first glance, great auroral storms seem more frequent in the second half of the interval. This could result from a more active Sun (Fig. 1 of Usoskin et al., 2011) and/or be an artifact of better record preservation and communications in last 250 years. The data from Figure 1 and Table 1 suggest the overall frequency of great auroral storms is approximately once every 40-60 years.

Markers in Figure 1 with larger radii correspond to more equatorward auroral events. Note that auroras viewed equatorward of $30^{\circ}$ MLAT does not mean that the auroral structures nor the auroral particle boundaries are at such a low latitude. For reference, Case et al. (2016) report that mid-to-high latitude auroras are typically visible from about $\sim 400 \mathrm{~km}$ equatorward of the actual auroral structure. Figure 1 of Vallance Jones, (1992) and Figure 2 of Nakazawa et al. (2004) suggest that low-latitude aurora might be viewed from $\sim 1000 \mathrm{~km}$ equatorward of the auroral structure location. Table 1 provides dates, auroral location in geographic coordinates, and additional source details about these events (note that we have intentionally kept the reference listings short and recent for the sake of educational brevity). Some of the events have multi-day, lowlatitude auroral sightings; these are shown as overlaid markers.

Annotations in Figure 1 highlight technology developments. Regular sunspot observations and development of magnetometers and electrical devices were the basis for understanding storm impacts during and after the 1859 Carrington-Hodgson storm (Carrington, 1859; Hodgson, 1859). Proliferation of electronic devices (and their susceptibility to space weather storms) continued apace in the 20th century, presenting the opportunity for broader societal consequences from storms with less intensity than those shown in Figure 1 (see Sects. 3 and 4). Some readers may recognize the multi-day Carrington-Hodgson 1859 storm as an archetype of great solar, auroral and geomagnetic storms (e.g., Cliver \& Dietrich, 2013 and references therein). The combination of a white light solar flare, followed shortly by low-latitude auroras and substantial mid-latitude 


\section{Years of Space Weather Storms with Aurora Visible at or Equatorward of $30^{\circ}$ Magnetic Latitude}

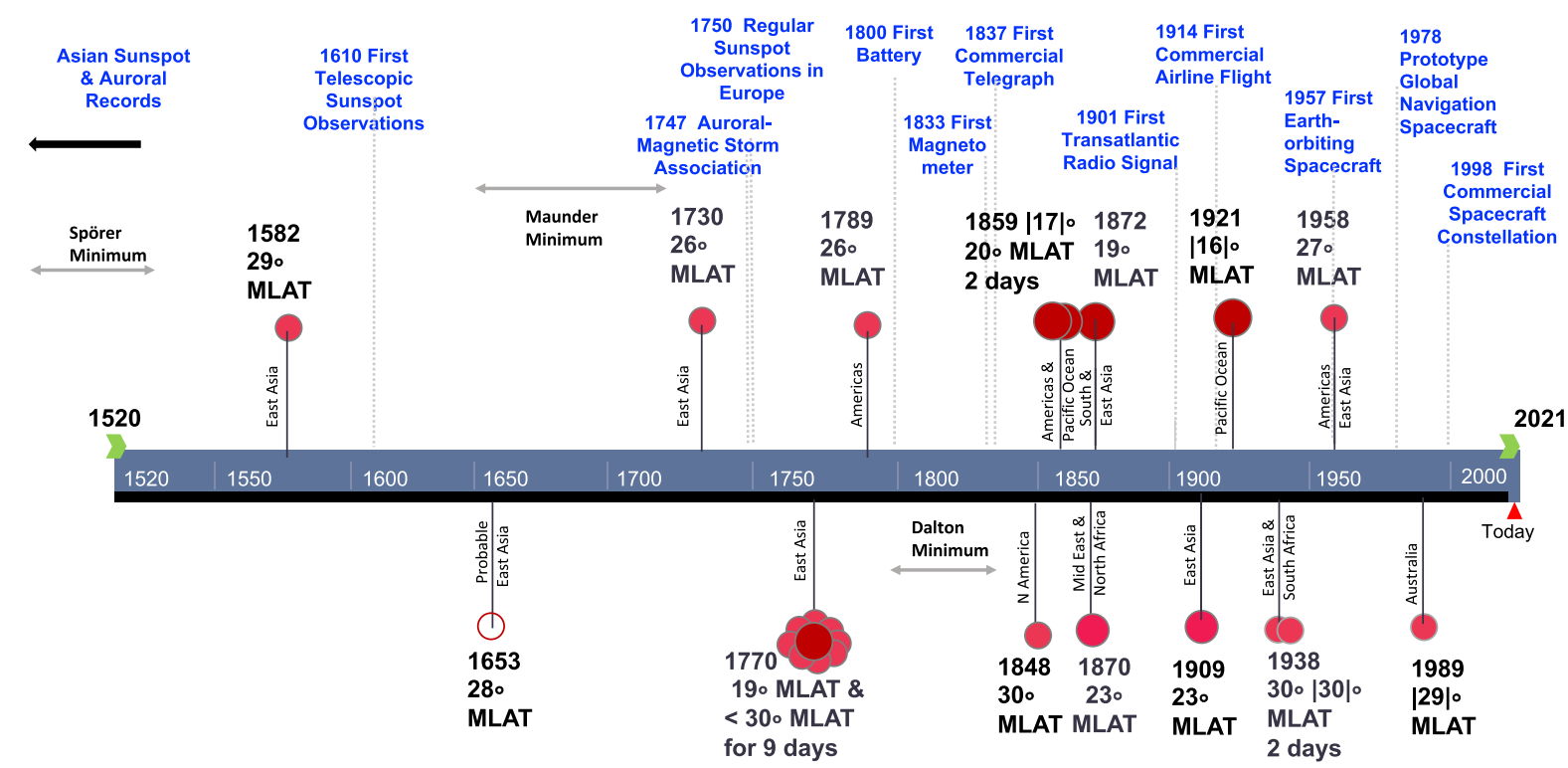

Fig. 1. Year and approximate magnetic latitude of lowest latitude report of visible aurora for storms spanning 500 years (1520-2020). The 14 events are placed above and below the timeline to avoid overlap. Brackets indicate southern latitudes. All MLAT values have been rounded to the nearest whole degree. Large circles correspond to more equatorward auroral visibility. An open marker indicates a probable event. See references in Table 1. Several technology developments are listed, as are the approximate intervals of grand/secular solar minima.

geomagnetically induced currents (GICs) have earned this storm a place in history. The 1859 storm ranks very high in many storm categories: flare intensity, magnetic disturbance intensity and auroral boundary location. In terms of aurora and magnetic disturbance it appears to fit into a broader population of great auroral storms (Hayakawa et al., 2019a; see also Chapman et al., 2020). Unusual aspects of the event include its multiday longevity of low-latitude auroras and its ranking as a top contender in most storm categories (Cliver \& Svalgaard, 2004)

Table 1 provides additional storm "measures" based on ground magnetic records when available. The Dst index, available from the Kyoto World Data Center (WDC for Geomagnetism, Kyoto, 2015), is often used as a measure of geomagnetic storm strength. We use it to provide context for the association between aurora and magnetic storm strength in these events. An approximate version of the Dst index extends back in time to 1932 as the Dcx Index (Karinen \& Mursula, 2005). Riley (2017) report some magnetometer saturation effects in the Dcx Index. These indices provide the surfaceobserved, longitudinally-averaged perturbation of Earth's near-equatorial external magnetic field measured at the surface. See Borovsky \& Shprits (2017) for interpretive cautions related to this class of geomagnetic indices.

Loewe \& Prölss (1997) assign magnetic categories for storm strength based on Dst: A strong storm is $-100 \mathrm{nT}>\mathrm{Dst}>-200$ $\mathrm{nT}$; a severe storm is $-200 \mathrm{nT}>$ Dst $>-350 \mathrm{nT}$, and a great storm is Dst $<-350$ nT. Eleven of the 14 storms in Figure 1 have Dst estimates that place them in the "severe" or "great" magnetic storm categories. Lacking magnetic measurements and the consequent uncertainty of storm-strength estimates prior to 1850 , we provide a descriptive storm-strength estimate rather than a numeric estimate of strength in Table 1 . See the starred references for values. Three storms do not yet have Dst estimates in the literature. Most of the recent storms also have short-lived rapid magnetic variations associated with sudden changes in the solar wind storm driver(s). These are called Sudden Commencements (SCs) or Storm Sudden Commencements (SSCs) if followed by a geomagnetic storm (Mayaud et al., 1973). Some of the storms are multi-day events with multiple SSCs. Information on SSCs since 1869 is available at http:// www.obsebre.es/en/rapid from the Ebro Observatory, where interpretive information about them is also provided.

Deeper investigations of the references in column four of Table 1 reveal that most great auroral events originate in large and/or complex sunspot regions. Such regions can be long-lived with extended transits across the solar disk. Further, multiple eruptions from such regions affect interplanetary space, potentially allowing for faster travel of ejecta emitted later in the series (Temmer et al., 2017). This scenario is the probable context for the double events in 1859 and 1938. The event in 1770 (Hayakawa et al., 2017) had visible auroras below $20^{\circ}$ MLAT for one night and visible aurora below $30^{\circ}$ MLAT for nine nights in a row. We suggest that based on duration, the 1770 event is a strong candidate for a once-in-500-year auroral storm designation, with the understanding that this was likely not a single eruptive event (See also Liu et al., 2019).

Another lesson from a deeper reading of the references in Table 1 is the association between great auroral storms and disruptive geomagnetically induced currents (GICs). Every great auroral storm after 1850 had reports of GICs in the long 
Table 1. Details of events in Figure 1: Date, geographic latitude/longitude, magnetic storm strength estimates (Dst or Dcx), and other relevant information from references or databases.

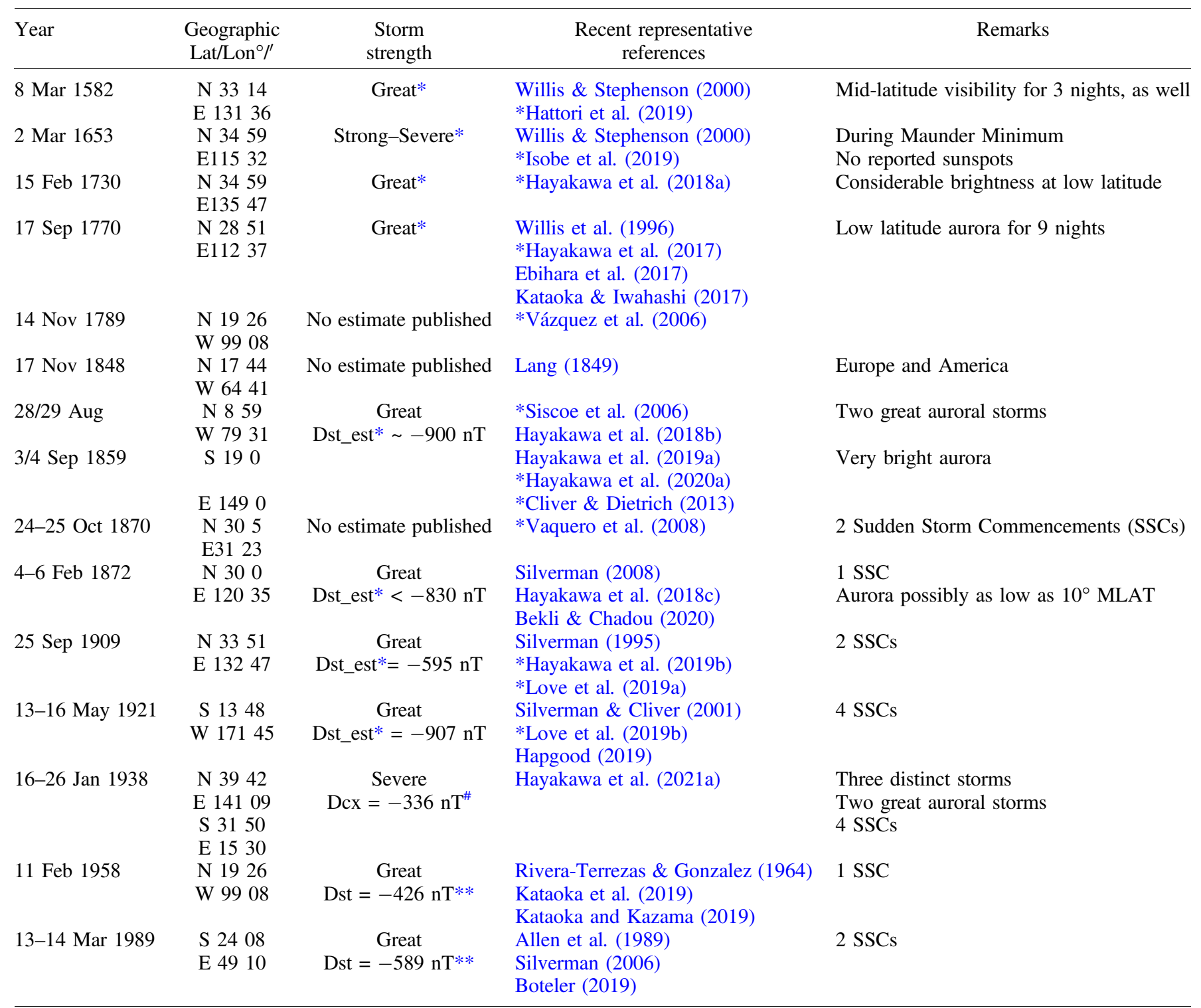

\footnotetext{
* Estimated storm strength from *citations,

${ }^{\#}$ Dex $=$ reconstructed Dst Index from University of Oulu http://dcx.oulu.fi/?link=main.

*** Dst from http://wdc.kugi.kyoto-u.ac.jp/dstdir/
}

electrically-conducting structures of the day. Over time these included telegraph lines, transoceanic communication cables, railways, some telephone lines and power grids. See Hapgood (2019) and Boteler (2019) for recent discussion of such problems.

It is natural to ask about storms on the CSAGI list that are not on Figure 1. We list these in Table 2 and note that there are eight such storms in an $\sim 70$-year span - about one per solar cycle. We briefly surveyed recent literature describing these events to determine if there were common characteristics. Table 2 shows that most of these events: 1) had reported equatorward auroral visibility around $40^{\circ}$ MLAT, and 2) are categorized as great magnetic storms according to the Dst or Dcx indices. Further, most were associated with disruptive technology effects that would have made them memorable to CSAGI attendees. The storm events in Table 2 seem similar in strength and intensity to that of the 20 November 2003 magnetic storm, during which red aurora were photographed from Athens, Greece (Ayiomamitis, 2003).

\section{Low latitude auroral storm and radio and aviation effects of January 1938 storms}

The sequencing of events in space weather storms can be mystifying to those outside the space weather field. In this section we offer an approach to organizing and communicating information about storm timing. We also list some of the space 
Table 2. CSAGI magnetic storm events with mid-latitude aurora.

\begin{tabular}{|c|c|c|c|c|}
\hline Date & $\begin{array}{l}\text { Approximate auroral } \\
\text { visibility }{ }^{\circ} \text { MLAT }\end{array}$ & Storm strength & Reference & Comment \\
\hline 17 and 22 Nov 1882 & 39 & $\begin{array}{c}\text { Great } \\
\text { Dst_est }=-386 \mathrm{nT}^{*}\end{array}$ & *Love (2018) & Telegraph disruptions (see reference) \\
\hline 31 Oct 1903 & 40 & $\begin{array}{c}\text { Great } \\
\text { Dst_est }=-531 \mathrm{nT}^{*}\end{array}$ & *Hayakawa et al. (2020b) & Telegraph disruptions (see reference) \\
\hline 16 April 1938 & 41 & $\begin{array}{c}\text { Severe } \\
\mathrm{Dcx}=-255 \mathrm{nT}^{*}\end{array}$ & $\begin{array}{l}\text { Nicholson \& } \\
\text { Sternberg-Mulders (1939) }\end{array}$ & \\
\hline 1 Mar 1941 & 35 & $\begin{array}{c}\text { Great } \\
\text { Dst_est } \leq-464 \mathrm{nT}^{*}\end{array}$ & Hayakawa et al. (2021b) & Polar cap absorption \\
\hline 18 Sep 1941 & Near 40 & $\begin{array}{c}\text { Great } \\
\operatorname{Dcx}=-359 \mathrm{nT}^{* *}\end{array}$ & $\begin{array}{l}\text { Love \& Coïsson (2016) } \\
\text { Albuquerque Journal (1941) } \\
\text { McNish (1941) }\end{array}$ & $\begin{array}{l}\text { Radio and grid disruption, } \\
\text { military impacts (see reference) }\end{array}$ \\
\hline 28 Mar 1946 & $<42$ & $\begin{array}{c}\text { Great } \\
\text { Dst_est } \leq-512 \mathrm{nT}\end{array}$ & Hayakawa, et al. (2020c) & $\begin{array}{l}\text { Radio disruption to transatlantic } \\
\text { aviation Odenwald (2007) }\end{array}$ \\
\hline
\end{tabular}

* Storm strength estimated from citations or published indices, Dcx = reconstructed Dst Index from University of Oulu.

** Storm Strength also reported as Dst/Dcx values in Cliver \& Svalgaard (2004).

Note some Dcx values may be derived from off scale-magnetograms and thus underestimate the actual magnitude.

\section{Late January 1938 Solar and Geomagnetic Storms}

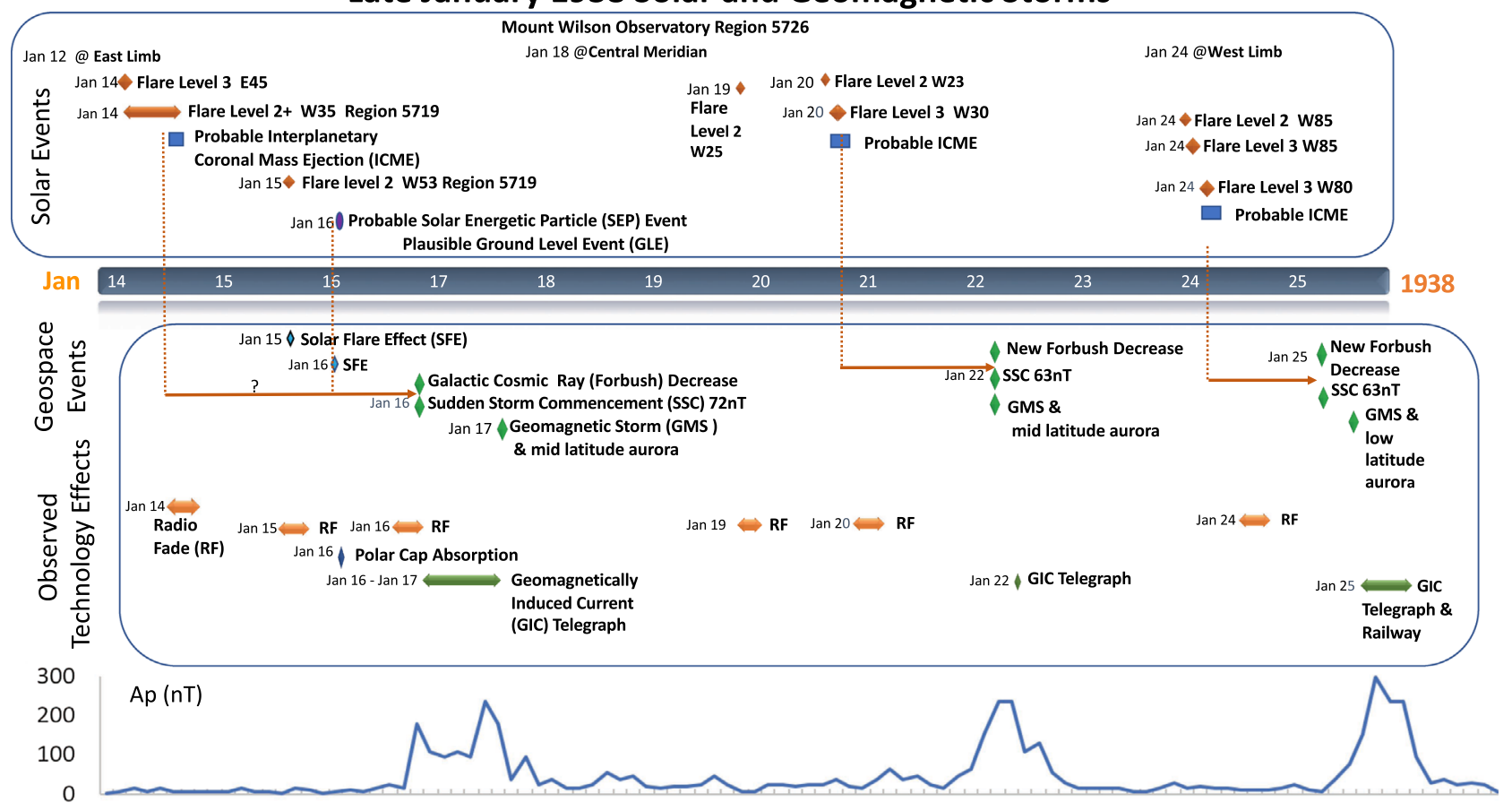

Fig. 2. A timeline of solar, geophysical and technology effects for the January 1938 storms. The two vertical lines for the first storm indicate a range of uncertainty about which solar storms or combinations thereof caused the geomagnetic disturbances on 16/17 January. Events and solar longitudes of flares are from data in Table 2 of Hayakawa et al. (2021a).

weather technology effects in the pre-World War II era. Figure 2 shows the sequence of events leading to the great auroral storm(s) of January 1938 - a storm in Nicolet's CSAGI list. This storm sequence occurred as the world was becoming more technology savvy and dependent. Bartels et al. (1939) described several aspects of the late January 1938 activity-interval to illustrate the newly developed $\mathrm{Kp}$ index, which characterized magnetic storm intensity based on data from widely distributed ground magnetometer stations. Figure 2 orders the information with solar emissions at the top, geophysical responses/geospace events in the middle section, and technology effects and the Ap index is at the bottom. For readers/users new to space weather, 
the Ap index is a linearized version of Bartel's $\mathrm{Kp}$ index. Students report that starting with an approximately linear index is a good segue into more in depth discussion of the quasilogarithmic Kp index.

The 21/22 and 25/26 January 1938 great auroral storms were the second and third in a series of geomagnetic storms associated with Mount Wilson Observatory-designated Region 5726 transit of the Earth-facing solar disk (Hayakawa et al., 2021a). These authors note that the large AR appeared at the solar East (E) limb on 12 January, crossed the central meridian on 18 January, and disappeared behind the West (W) limb on 24 January. There were numerous solar flares through the interval. The flare level (importance) in hydrogen alpha $(\mathrm{H} \alpha=656.28 \mathrm{~nm})$ emission indicates the $\mathrm{H} \alpha$ flaring area in millionths of a solar hemisphere (msh) ( $1=100-250 \mathrm{msh} ; 2=250-600 \mathrm{msh}$; and $3>600 \mathrm{msh}$ ). There were also three distinct intervals of high geomagnetic activity, the latter of which continued well after the AR had rotated off the visible solar disk. Based on time between flares and sudden storm commencements, Hayakawa et al. (2021a) suggest there were at least three ICMEs that arrived at Earth on 16, 22 and 25 January 1938. These are listed as "probable" in Figure 2, since there were no appropriate measurements to verify the solar wind disturbances. These had estimated average velocities of $1900 \mathrm{~km} / \mathrm{s}$, $1370 \mathrm{~km} / \mathrm{s}$, and $1260 \mathrm{~km} / \mathrm{s}$, respectively. The 25-26-January storm associated with the latter solar event is identified by Jones (1955) as being in the top $10 \%$ of 112 great magnetic storms between 1874 and 1954 .

We use the information in Table 2 of Hayakawa et al. (2021a) to show how such ongoing events and effects can be visually structured to help students and novices in the field of space weather make sense of space weather storms. Vertical dotted bars on Figure 2 are intended to link solar activity with the subsequent geomagnetic activity. Figure 2 suggests that the complex AR was hyperactive, producing ejecta that strongly interacted with the near-Earth environment. AR 5726 emitted an intense solar flare $(\mathrm{H} \alpha$, Importance level 3) as it arrived at $\mathrm{E}$ 45 solar longitude. Other areas were also flaring, so it is challenging to fully associate flares with probable ICMEs. The first strong geomagnetic activity developed at Earth in just over two days, with a SSC late on 16 January. The associated ICME likely would have moved through relatively dense solar wind somewhat slowing its arrival at Earth relative to subsequent events. Strong galactic cosmic ray (GCR) decreases (noted by Forbush, 1938 and now called "Forbush Decreases") were observed. These are indicative of large interplanetary ejecta that scatter GCR particles back to space. After the first ICME swept through interplanetary space, the ICMEs from subsequent eruptions should have traveled through a less dense solar wind and arrived at Earth more quickly. The shorter horizontal arrows indicate this timing. The first ICME arrival produced midlatitude aurora and a strong geomagnetic storm, while the second ICME produced a low-latitude aurora visible at $30^{\circ}$ MLAT and a severe geomagnetic storm on 22 January. The final storm (25 January) followed a level 3 solar flare at West 85 solar longitude and produced aurora visible at $30^{\circ}$ MLAT. By the time the third ICME arrived at Earth the AR had rotated to the far side of the Sun (see over-the-limb loops in Fig. 4, Nicholson, 1938). Researchers of the day marveled that a great storm could occur in the absence of a visible sunspot.
Accompanying the natural phenomena was a series of technology impacts. These included radio fades, which can be caused by solar flares and/or mid-latitude ionospheric disturbances during magnetic storms, and polar cap absorption of radio signals, which are caused by excess ionization by SEPs. Geomagnetically induced currents affected telegraph systems worldwide and train operations in the United Kingdom (Odenwald, 2007). The significant radio blackouts reported by US airlines added urgency to the US Department of Commerce National Bureau of Standards' efforts to establish high frequency (HF) radio forecasting capability within its Radio Section (see historical discussions and references in Caldwell et al., 2017). There were ongoing radio fades during January 1938. These were probably more pervasive than shown, as such reports are still under active investigation. Finally, GICs appeared with each SSC. This indicates fast compressions of Earth's magnetosphere and strong storming after the compressions.

The January 1938 series of storms exemplifies the pattern of numerous other storms discussed in the recent literature: a large, extremely active sunspot complex, with a multi-day solar disk transit that ejects a sequence of ICMEs. The later ICMEs quickly move through the partially evacuated channels cleared by the previous ICMEs. Bright aurora appeared at mid-latitudes during all three storms in the sequence and particularly at low latitudes during the final two storms.

This event offers valuable lessons in the basic development of space weather storms. There are aspects of solar, heliospheric, geomagnetic and societal impacts. The latter included telegraph outages, railway disruptions and radio interference in communications and aviation applications. The individual events are well-enough separated that cause-effect relationships are fairly straightforward to describe. In subsequent decades disruptions of space-based applications have add new dimensions to space weather storm complexity and challenges is sorting timing and causes, as we illustrate in the section and figure below.

\section{December 2006 storm event timeline}

In this section we discuss an event in December 2006 with many solar behaviors in common with the January 1938 great auroral storm, whereas the aurora only extended only to about 40 MLAT and the geomagnetic storm level (Dst $=-147 \mathrm{nT}$ on 15 December) was less intense than most of the events on the CSAGI list. While this event was not a great auroral storm, its far-ranging effects on space-age technology provide context for planning for future storms. Figure 3 illustrates the effects of an unanticipated nest of solar activity in December 2006, when the Sun was in the late declining phase of solar cycle 23 . We note that better understanding of such events and more technology impacts produce a visually "busier" graphic. We will not delve into every aspect, since a full investigation would require a much lengthier explanation.

The stormy interval of 5-17 December 2006 began with the appearance of NOAA AR 10930 on the Sun's Eastern limb late on 4 December. The extreme East limb location ( E80) prevented a good view of the AR. With no warning the region emitted an X9.0 flare on 5 December. The probable first ICME was not Earth-directed, however detectors on spacecraft 


\section{December 2006 Solar and Geomagnetic Activity Events}

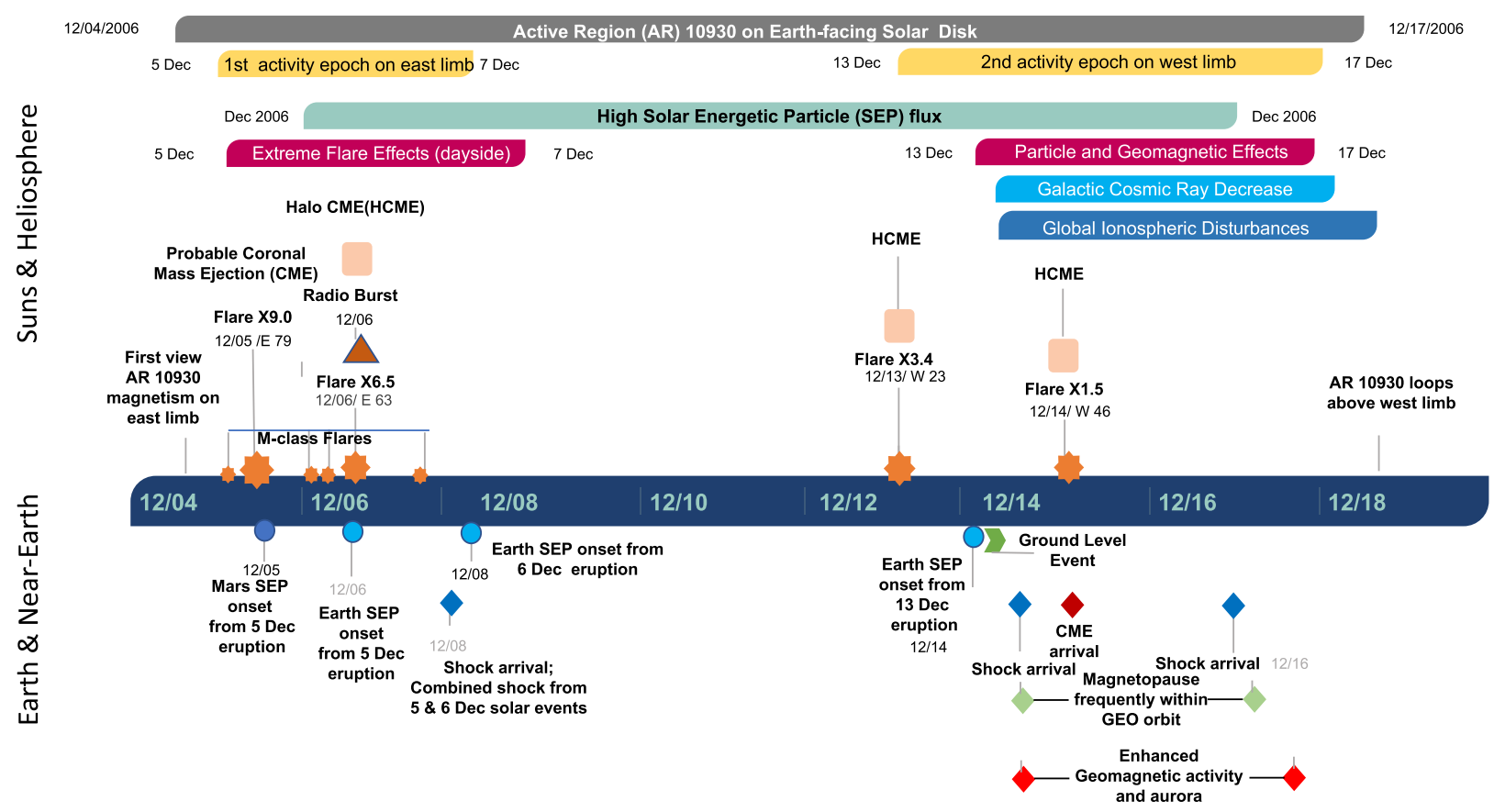

(a)

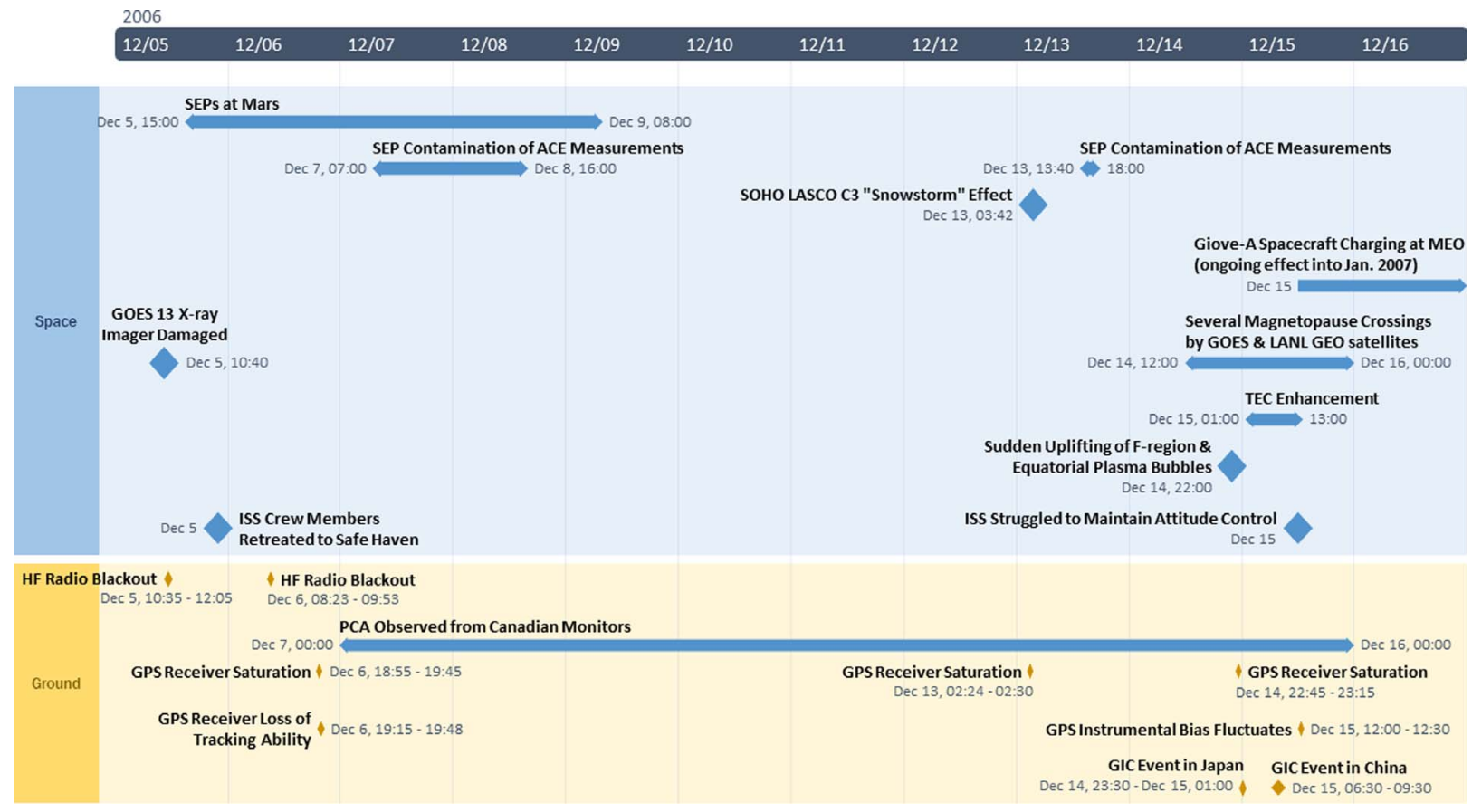

(b)

Fig. 3. A two-panel timeline of solar, geophysical and technology effects for the December 2006 storms. a) Solar and interplanetary aspects of the event; longitudes of major flares are provided. b) Technology effects and is slightly expanded with respect to panel a. Event start/stop times and thresholds are in the references cited in this section.

at Mars and Venus suggest that such a structure passed these planets (Futaana et al., 2008; McKenna-Lawlor et al., 2008). The following day AR 10930 hosted an X6.5 flare and the largest radio burst ( $>10^{6}$ solar flux units) ever recorded at the Global Positioning System (GPS) frequency of $1.575 \mathrm{GHz}$ (Cerruti et al., 2008). A substantial SEP event and a halo 
CME followed. Technology effects were immediate, with permanent damage to the GOES 13 Solar X-ray Imager (NGDC, 2007) and sudden saturation of dayside GPS ground receivers causing GPS outages throughout the American sector (Cerruti et al., 2008). Although ISS crew members were instructed to retreat to safe haven on 5 December, the eastern location of the event delayed the arrival of energetic particles at Earth. Loss of data from SEP-sensitive instruments on the ACE spacecraft started $\sim 07$ UT on 8 December (McKenna-Lawlor et al., 2008). An HF radio polar cap absorption (PCA) event began about the same time and continued intermittently until 16 December.

After 7 December, AR 10930 quieted until new solar magnetic flux began to emerge near the site of the previous activity on 10 December. Early on 13 December the AR, which was by then better positioned for geoeffective activity, produced an X3.4 flare, another broad (halo) ICME and another SEP event that almost immediately caused a ground level event (GLE-70), recorded by ground-based neutron monitors (Matthiä et al., 2009). The SEP event nearly blinded the Solar Heliospheric Observatory (SOHO) imager that was tracking the advancing ICME (Kataoka et al., 2009). The associated solar wind shock arrived at Earth's L1 point after only $35.5 \mathrm{~h}$ (McKenna-Lawlor et al., 2008), with the driver ICME arriving about $8 \mathrm{~h}$ later (Zhou et al., 2011). The shock and interplanetary magnetic field (IMF) structures following the shock brought the magnetopause to within geosynchronous orbit for part of the subsequent $12 \mathrm{~h}$. Southward IMF in this ICME expanded the polar cap and allowed very energetic particles from the ongoing SEP event to access mid-latitudes (Adriani et al., 2016), thus expanding the polar cap HF radio outages.

Additionally, strong southward IMF "opened" the magnetosphere to substantial energy input, which was quickly shared with geospace. NASA reported that the ISS crew struggled to maintain attitude control. The ionospheric F-layer was subject to extreme enhancement and uplift as well as large interhemispheric asymmetries (Suvorova et al., 2013). Some monitored power grids in Asia reported geomagnetically induced currents (Watari et al., 2009; Ni, 2018). Within a few hours the European Giove, a research spacecraft in medium Earth orbit began reporting spacecraft charging effects that continued into January 2007 (Fig. 12, Cannon, 2013) as Earth's radiation belts were energized and remained so for weeks (Tverskaya et al., 2008).

Although auroras were reported only to mid-latitudes - a faint auroral red glow was noted from Payson AZ in the US $\left(\sim 44^{\circ}\right.$ MLAT), the mid-latitude ionosphere was significantly disturbed. The GPS measured strong Total Electron Content (TEC) variations and plasma irregularities (Pedatella et al., 2009; Zhang et al., 2009) at mid- and high-latitudes. These combined factors led to elevated GPS positioning errors in the tens-of-meters range in the horizontal and vertical directions, respectively, during this event (Carrano et al., 2009).

\section{Discussion and summary}

This article is dedicated to visualizing and sharing information about space weather and space climate. Our example timelines cover a range of complexity. We used a storm list created prior to the IGY as starting point to chart the great auroral storms of the last 500 years. Further surveys should reveal additional events. To provide a visual perspective on the frequency of great auroral events, Figure 1 presents 14 events with auroral visibility at or equatorward of $30^{\circ}$ MLAT. We find that on average a great auroral storm appears about every four to five solar cycles, whereas the distribution is temporally uneven with the Sun apparently modulating the distribution as it cycles through grand minima and maxima. The sparse auroral records prior to 1850 and probable inability to identify some storms due to terrestrial cloudiness during any part of the record lead us to believe that such storms could be more frequent. Others may yet be discovered. One event in 1770 stands out as an especially long-lasting auroral event, whereas there are other events during which the auroral were observed at more equatorward locations.

Figure 1 provides a visual guide to great auroral storms of the last 500 years, however auroral visibility boundaries are insufficient for full storm description. Students and novices will ultimately learn that space weather operators rely on an array of storm measures for conveying storm strength. Greater insight can be gained with ground-based magnetic measures (Table 1), radio measures as in Section 3 and 4, and from space-based measures as in Section 4. Additional learning opportunities for students and novices could include plotting these storms according to a storm strength index or sunspot number, when those data are available, or plotting the data in context with cultural/technology/industrialization activity. Students and novices interested in reading the literature cited in Table 1 can compare and contrast the reported longevity of solar active regions associated with these storms or look more deeply into the associated geomagnetic disturbances for the post-1850 events. An additional worthy discussion point could be related to the possible effects of a quasi-9-day-long great auroral event on modern space systems. In particular, low earth orbiting spacecraft (and space debris) would likely feel long-term atmospheric drag and attitude control effects from such an event.

To demonstrate the effects of space weather storms on society and technology, we illustrate two events. The first of these was associated with a series of solar eruptions and geomagnetic storms in January 1938; a time of increasing reliance on radio technology, but still strong use of telegraph systems. The storms created awe-inspiring aurora and silenced telegraph and radio communications. Figure 2 shows a sequence of three storms in early 1938 , with numerous solar flares and probable high-speed ejecta directed at Earth. The ability to recognize and categorize flares was still cutting-edge technology at the time. More reliance on technology at the time meant more space weather susceptibility. The 1938 event appears to be the first multi-day storm to have wide effects on commercial aviation documented in newspapers. This event supports the discussion of the typical sequencing and time delays associated with space weather storms. There are a number of basic concepts (and acronyms) for this event that are worthy of attention in a classroom or group-discussion setting.

A more "moderate" event in late 2006 is our final storm timeline. Space systems bore the wrath of that storm. Space weather X-ray monitors were damaged by intense X-rays. Solar energetic particles blinded some imagers. Some space plasma measurements for space weather operations were interrupted. 
GPS navigation and guidance were interrupted. After passage of the solar wind shock geospace was greatly disturbed. In the upheaved thermosphere the International Space Station crew struggled to maintain attitude control while the space shuttle Discovery was docked. While only minor geomagnetically induced current influences were reported on high-latitude power grids there were significant disturbances in Earth's ionosphere leading to single frequency GPS positioning errors. Earth's radiation belts were enhanced for several weeks. Instrumentation at other planets also recorded effects of the storm.

Although the 14-16 December 2006 geomagnetic storm did not rate as severe storm on the Dst scale, the long list of associated technology challenges suggests that any single storm-scale is likely to fail at adequately describing the possible effects of complex active regions. These ARs can produce multiple or single fast ejecta and possibly interact with and/or pre-condition geospace to be sensitive to less-than-extreme storm drivers. This event is a candidate for case study and scenario-based exercises.

Here are several important points discussed by students involved in this project that we deem important for teaching and learning about space weather. 1) There is no comprehensive space weather scale or index that can cover the multitude of space weather responses at Earth. 2) Further, descriptive terms like strong, super, great or extreme have different meanings within the sub-disciplines in space weather. 3) Sequencing of storm drivers and pre-conditioning of the geospace environment can be difficult to disentangle and produce results very different from what might be anticipated. 4) Despite more than 500 years of great auroral storms, we are only at the beginning of forecasting space weather.

Development of timelines for this article is an outcome of independent study projects using historical literature searches, guided journal-article reading and archival searches via site visits and the Internet. Students and novices reported that learning new terminology and cause-and-effect timing in the context of actual events helped solidify their grasp of space weather events. We plan to extend space weather timelines to more interactive platforms, such as web-based interactive formats or toolkits to investigate different scenarios. Better understanding of space weather interactions will require a level of visualization not possible with two-dimensional diagrams, however such diagrams are a good starting point.

Acknowledgements. DJK is grateful to have students lead visualization projects for this manuscript. Their efforts provided the groundwork for extending this type of data visualization to other space weather storm sequences of interest. DJK and KW were partially supported by AFOSR Award No: FA9550-17-1-0258. VB was partially supported by AFOSR MURI Award FA9550-16-1-0364. HH was partially funded by JSPS Grant-in-Aids JP15H05812, JP17J06954, JP20K22367, JP20K20918, and JP20H05643, JSPS Overseas Challenge Program for Young Researchers, the 2020 YLC collaborating research fund, and the research grants for Mission Research on Sustainable Humanosphere from Research Institute for Sustainable Humanosphere (RISH) of Kyoto University and Young Leader Cultivation (YLC) program of Nagoya University. DJK and HH have been benefited from discussions within the ISSI International Team \#510 (SEESUP Solar Extreme Events: Setting Up a
Paradigm). The results presented in this paper use the Dcx index provided by the Dcx server of the University of Oulu, Finland, at http://dcx.oulu.fi. The Dst Index is provided by World Data Center for Geomagnetism, Kyoto, http://wdc. kugi.kyoto-u.ac.jp/dstdir/. The official Ap index is provided by GFZ, Adolf-Schmidt-Observatory Niemegk, https://www. gfz-potsdam.de/en/kp-index/. Information on SSCs is provided by the Ebro Observatory http://www.obsebre.es/en/ rapid. The Ap data were made available for easy download via the University of Colorado Space Weather Technology Research and Education Center Space Weather Portal, https://lasp.colorado.edu/space-weather-portal/home. This paper is written as a tribute to Baron (Professor) Marcel Nicolet's vision of inclusiveness in bringing geophysical data, people and countries together for the benefit of science and humanity. Over his long career, and especially as a leader in CSAGI, Marcel Nicolet studied many aspects of nature that are currently included within the discipline of space weather. Some of this research was motivated by a lecture given by DJK at the 2019 Haystack Observatory Michael Buonsanto Memorial Lecture.

\section{References}

Adriani O, Barbarino GC, Bazilevskaya GA, Bellotti R, Boezio M, et al. 2016. PAMELA's measurements of geomagnetic cutoff variations during the 14 December 2006 storm. Space Weather 14: 210-220. https://doi.org/10.1002/2016SW001364.

Albuquerque Journal. 1941. Vol. 250, Albuquerque NM, USA, 17 p.

Allen J, Sauer H, Frank L, Reiff P. 1989. Effects of the March 1989 solar activity. Eos Trans AGU 70(46): 1479-1488. https://doi.org/ 10.1029/89EO00409.

Araki T. 2014. Historically largest geomagnetic sudden commencement (SC) since 1868. Earth Planet Space 66: 164. https://doi.org/ 10.1186/s40623-014-0164-0.

Ayiomamitis A. 2003. http://www.perseus.gr/Astro-Aurorae-20031120001.htm, Accessed 5 Feb 2020.

Bartels J, Heck NH, Johnston HF. 1939. The three-hour-range index measuring geomagnetic activity. Terr Magn Atmos Electr 44(4): 411-454. https://doi.org/10.1029/TE044i004p00411.

Bekli MR, Chadou I. 2020. Records of auroras in Arabic historical sources: Additional list and preliminary analysis. Solar Phys 295: 3. https://doi.org/10.1007/s11207-019-1567-7.

Borovsky JE, Shprits YY. 2017. Is the Dst index sufficient to define all geospace storms? J Geophys Res (Space Phys) 122: 11543 11547. https://doi.org/10.1002/2017JA024679.

Boteler DH. 2019. A 21st century view of the March 1989 magnetic storm. Space Weather 17: 1427-1441. https://doi.org/10.1029/ 2019SW002278.

Caldwell B, McCarron E, Jonas S. 2017. An abridged history of federal involvement in space weather forecasting. Space Weather 15: 1222-1237. https://doi.org/10.1002/2017SW001626.

Cannon PS. 2013. Extreme space weather: Impacts on engineered systems. Royal Academy of Engineering, London, UK. https:// www.raeng.org.uk/publications/reports/space-weather-full-report.

Carrington RC. 1859. Description of a singular appearance seen in the sun on September 1, 1859. Mon Notic Roy Astron Soc 20: 13-15. https://doi.org/10.1093/mnras/20.1.13.

Carrano CS, Bridgwood CT, Groves KM. 2009. Impacts of the December 2006 solar radio bursts on the performance of GPS. Radio Sci 44: RS0A25. https://doi.org/10.1029/2008RS004071. 
Case NA, MacDonald EA, Viereck R. 2016. Using citizen science reports to define the equatorial extent of auroral visibility. Space Weather 14: 198-209. https://doi.org/10.1002/2015SW001320.

Cerruti AP, Kintner PM, Gary DE, Mannucci AJ, Meyer RF, Doherty P, Coster AJ. 2008. Effect of intense December 2006 solar radio bursts on GPS receivers. Space Weather 6: S10D07. https://doi.org/10.1029/2007SW000375.

Chapman SC, Horne RB, Watkins NW. 2020. Using the aa index over the last 14 solar cycles to characterize extreme geomagnetic activity. Geophys Res Lett 47: e2019GL086524. https://doi.org/ 10.1029/2019GL086524.

Cliver EW, Svalgaard L. 2004. The 1859 solar-terrestrial disturbance and the current limits of extreme space weather activity. Sol Phys 224: 407-422. https://doi.org/10.1007/s11207-005-4980-z.

Cliver EW, Dietrich WF. 2013. The 1859 space weather event revisited: limits of extreme activity. J. Space Weather Space Clim 3: A31. https://doi.org/10.1051/swsc/2013053.

Ebihara Y, Hayakawa H, Iwahashi K, Tamazawa H, Kawamura AD, Isobe H. 2017. Possible cause of extremely bright aurora witnessed in East Asia on 17 September 1770. Space Weather 15: 1373-1382. https://doi.org/10.1002/2017SW001693.

Forbush SE. 1938. On cosmic-ray effects associated with magnetic storms. Terr Magn Atmos Electr 43: 203-218. https://doi.org/ 10.1029/TE043i003p00203.

Futaana Y, Barabash S, Yamauchi SM, McKenna-Lawlor S, Lundin R, et al. 2008. Mars express and venus express multi-point observations of geoeffective solar flare events in December 2006. Planet Space Sci 56(6): 873-880. https://doi.org/10.1016/j.pss.2007.10.014.

Hattori K, Hayakawa H, Ebihara Y. 2019. Occurrence of great magnetic storms on 6-8 March 1582. Mon Notic Roy Astron Soc 487: 3550. https://academic.oup.com/mnras/article/487/3/3550/5522353.

Hapgood M. 2019. The great storm of May 1921: An exemplar of a dangerous space weather event. Space Weather 17: 950-975. https://doi.org/10.1029/2019SW002195.

Hayakawa H, Iwahashi K, Ebihara Y, Tamazawa H, Shibata K, et al. 2017. Long-lasting extreme magnetic storm activities in 1770 found in historical documents. Astrophys J Lett 850: L31. https://doi.org/10.3847/2041-8213/aa9661.

Hayakawa H, Ebihara Y, Vaquero JM, Hattori K, Carrasco VMS, et al. 2018a. A great space weather event in February 1730. A\&A 616: A177. https://doi.org/10.1051/0004-6361/201832735.

Hayakawa H, Ebihara Y, Hand DP, Hayakawa S, Kumar S, Mukherjee S, Veenadhari B. 2018b. Low-latitude aurorae during the extreme space weather events in 1859. Astrophys $J$ 869: 57. https://doi.org/10.3847/1538-4357/aae47c.

Hayakawa H, Ebihara Y, Willis DM, Hattori K, Giunta AS, et al. 2018c. The great space weather event during 1872 February recorded in East Asia. Astrophys J 862: 15. https://doi.org/ 10.3847/1538-4357/aaca40.

Hayakawa H, Ebihara Y, Willis DM, Toriumi S, Iju T, Hattori K, et al. 2019a. Temporal and spatial evolutions of a large sunspot group and great auroral storms around the Carrington event in 1859. Space Weather 17: 1553-1569. https://doi.org/10.1029/2019SW002269.

Hayakawa H, Ebihara Y, Cliver EW, Hattori K, Toriumi S, et al. 2019b. The extreme space weather event in September 1909. Mon Notic Roy Astron Soc 484: 3. https://doi.org/10.1093/mnras/sty3196.

Hayakawa H, José RR, Yusuke E, Correia AP, Sôma M. 2020a. South American auroral reports during the Carrington storm. Earth, Planets Space 72: 1. https://doi.org/10.1186/s40623-020-01249-4.

Hayakawa H, Ribeiro P, Vaquero JM, Gallego MC, Knipp DJ, et al. 2020b. The extreme space weather event in 1903 October/ November: An outburst from the quiet Sun, 2020. Astrophys $J$ Lett 897: L10. https://doi.org/10.3847/2041-8213/ab6a18.
Hayakawa H, Ebihara Y, Pevtsov AA, Bhaskar A, Karachik N, Oliveira DM. 2020c. Intensity and time series of extreme solarterrestrial storm in March 1946. Mon Notic Roy Astron Soc 497: 5507-5517. https://doi.org/10.1093/mnras/staa1508.

Hayakawa H, Hattori K, Pevtsov AA, Ebihara Y, Shea MA, et al. 2021a. The intensity and evolution of the extreme solar and geomagnetic storms in 1938 January. Astrophys J 909: 197. https://doi.org/10.3847/1538-4357/abc427.

Hayakawa H, Blake SP, Bhaskar A, Hattori K, Oliveira DM, Ebihara Y. 2021b. The extreme space weather event in 1941 February/March. Astrophys J 908: 209. https://doi.org/10.3847/ 1538-4357/abb772.

Hiorter OP. 1747. Om magnet-nålens åtskillige ändringar, som af framledne professoren herr And. Celsius blifvit i akt tagne och sedan vidare observerade, samt nu framgifne. Kongl Svenska Vetenskaps Academiens Handlingar 8: 27-43.

Hodgson R. 1859. On a curious Appearance seen in the Sun. Mon Notic Roy Astron Soc 20: 15-16. https://doi.org/10.1093/mnras/ 20.1.15.

Isobe $\mathrm{H}$, Ebihara $\mathrm{Y}$, Kawamura $\mathrm{AD}$, Tamazawa $\mathrm{H}$, Hayakawa $\mathrm{H}$. 2019. Intense geomagnetic storm during Maunder minimum possibly by a quiescent filament eruption. Astrophys $J$ 887: 7. https://doi.org/10.3847/1538-4357/ab107e.

Jones HS. 1955. Sunspot and geomagnetic-storm data derived from Greenwich Observations 1874-1954. Her Majesty's Stationery Office, London. ftp://ftp.ngdc.noaa.gov/STP/SOLAR_DATA/SOLAR_ OBSERVATION/GREENWICH/Greenwich_SunspotStorm.pdf.

Kataoka R, Ebisuzaki T, Kusano K, Shiota D, Inoue S, Yamamoto TT, Tokumaru M. 2009. Three-dimensional MHD modeling of the solar wind structures associated with 13 December 2006 coronal mass ejection. J Geophys Res 114: A10102. https://doi.org/ 10.1029/2009JA014167.

Kataoka R, Iwahashi K. 2017. Inclined zenith aurora over Kyoto on 17 September 1770: Graphical evidence of extreme magnetic storm. Space Weather 15: 1314-1320. https://doi.org/10.1002/ 2017SW001690.

Kataoka R, Kazama S. 2019. A watercolor painting of northern lights seen above Japan on 11 February 1958. J Space Weather Space Clim 9: A28. https://doi.org/10.1051/swsc/2019027.

Kataoka R, Uchino S, Fujiwara Y, Fujita S, Yamamoto K. 2019. Fan-shaped aurora as seen from Japan during a great magnetic storm on 11 February 1958. J Space Weather Space Clim 9: A16. https://doi.org/10.1051/swsc/2019013.

Karinen A, Mursula K. 2005. A new reconstruction of the Dst index for 1932-2002. Ann Geophys 23: 475-485. https://doi.org/ 10.5194/angeo-23-475-2005.

Lang AS. 1849. On the aurora borealis of Nov. 17, 1848. Mont Not Roy Astron Soc 9: 148. https://doi.org/10.1093/mnras/ 9.6.148.

Liu YD, Zhao X, Hu H, Vourlidas A, Zhu B. 2019. A comparative study of 2017 July and 2012 July complex eruptions: are solar superstorms "perfect storms" in nature? ApJS 241: 15. https://doi. org/article/10.3847/1538-4365/ab0649.

Love JJ. 2018. The electric storm of November 1882. Space Weather 16: 37-46. https://doi.org/10.1002/2017SW001795.

Love JJ, Coïsson P. 2016. The geomagnetic blitz of September 1941. Eos 97. https://doi.org/10.1029/2016EO059319.

Love JJ, Hayakawa H, Cliver EW. 2019a. On the intensity of the magnetic superstorm of September 1909. Space Weather 17(1): 37-45. https://doi.org/10.1029/2018SW002079.

Love JJ, Hayakawa H, Cliver EW. 2019b. Intensity and impact of the New York Railroad superstorm of May 1921. Space Weather 17: 1281-1292. https://doi.org/10.1029/2019SW002250. 
Loewe CA, Prölss GW. 1997. Classification and mean behavior of magnetic storms. J. Geophys Res 102(A7): 14209-14213. https://doi.org/10.1029/96JA04020.

Maden N. 2020. Historical aurora borealis catalog for Anatolia and Constantinople (hABcAC) during the Eastern Roman Empire period: implications for past solar activity. Ann Geophys 38: 4. https://doi.org/10.5194/angeo-38-889-2020.

Matthiä D, Heber B, Reitz G, Sihver L, Berger T, Meier M. 2009. The ground level event 70 on December 13th, 2006 and related effective doses at aviation altitudes. Radiat Prot Dosim 136(4): 304-310. https://doi.org/10.1093/rpd/ncp141.

Mayaud PN, International Union of Geodesy and Geophysics, International Association of Geomagnetism and Aeronomy. 1973. A hundred year series of geomagnetic data, 1868-1967: Indices aa storm sudden commencements. IUGG Publications Office, Paris.

McKenna-Lawlor SMP, Dryer M, Fry CD, Smith ZK, Intriligator DS, et al. 2008. Predicting interplanetary shock arrivals at Earth, Mars, and Venus: A real-time modeling experiment following the solar flares of 5-14 December 2006. J Geophys Res 113: A06101. https://doi.org/10.1029/2007JA012577.

McNish AG. 1941. The Aurora and Geomagnetic Storm of September 18-19, 1941. Terr Magn Atmos Electr 46(4): 461-463. https://doi. org/10.1029/TE046i004p00461.

Nakazawa Y, Okada K, Shiokawa K. 2004. Understanding the "SEKKI" phenomena in Japanese historical literatures based on the modern science of low-latitude aurora. Earth Planets Space $\mathbf{5 6}$. https://doi.org/10.1186/BF03353323.

NGDC, National Geophysical Data Center, NOAA. 2007. https://sxi. ngdc.noaa.gov/docs/goes13_sxi_anomaly_20061205_v1.pdf, accessed 17 December.

Ni YY. 2018. The statistical analysis of the Geomagnetically Induced Current events occurred in Guangdong, China during the declining phase of solar cycle 23 (2003-2006). IOP Conf Ser Mater Sci Eng 339(1): 012013. https://doi.org/10.1088/1757-899X/339/1/012013.

Nicholson SB. 1938. The great sunspot of January 1938. Eos Trans AGU 19(1): 203-204. https://doi.org/10.1029/TR019i001p00203.

Nicholson SB. 1940. The great magnetic storm of March 24, 1940. Publ Astron Soc Pac 52(307): 169. https://doi.org/10.1086/125156.

Nicholson SB, Sternberg-Mulders E. 1939. Sunspot Activity during 1938. Publ Astron Soc Pac 51(299): 51. https://doi.org/10.1086/ 124999.

Nicolet M (Ed). 1959. The International Geophysical Year Meetings Annals of the International Geophysical Year, Vol. 2, Chap 7: The CSAGI Western Hemisphere Regional Conference, 16-20 July 1956, Rio de Janeiro. Permagon Press. ebook ISBN: 9781483226392.

Odenwald S. 2007. Newspaper reporting of space weather: End of a golden age. Space Weather 5: S11005. https://doi.org/10.1029/ 2007 SW000344.

Pedatella NM, Lei J, Larson KM, Forbes JM. 2009. Observations of the ionospheric response to the 15 December 2006 geomagnetic storm: Long-duration positive storm effect. J Geophys Res 114: A12313. https://doi.org/10.1029/2009JA014568.

Riley P. 2017. Statistics of extreme space weather events. In: Extreme Events in Geospace: Origins, Predictability, and Consequences, Buzulkova N, (Ed.), Elsevier, Amsterdam. pp. 115-138. https://www.sciencedirect.com/book/9780128127001/extreme-eventsin-geospace.

Rivera-Terrezas L, Gonzalez CG. 1964. La Rafaga Solar Del Dia 9 De Febrero De 1958. Boletin de los Observatorios de Tonantzintla Y Tacubaya 3: 25. https://www.astroscu.unam.mx/ bott/indexvol3num25.html.
Silverman SM. 1995. Low latitude auroras: The storm of 25 September 1909. J Atmos Terr Phys 57: 673-685. https://doi.org/ 10.1016/0021-9169(94)E0012-C.

Silverman SM. 2006. Comparison of the aurora of September 1/2, 1859 with other great auroras. Adv Space Res 38(2): 136-144. https://doi.org/10.1016/j.asr.2005.03.157.

Silverman SM. 2008. Low-latitude auroras: The great aurora of 4 February 1872. J Atmos Sol Terr Phys 70(10): 1301-1308. https://doi.org/10.1016/j.jastp.2008.03.012.

Silverman SM, Cliver EW. 2001. Low-latitude auroras: The magnetic storm of 14-15 May 1921. J Atmos Sol Terr Phys 63 (5): 523-535. https://doi.org/10.1016/S1364-6826(00)00174-7.

Silverman SM, Hayakawa H. 2021. The Dalton minimum and John Dalton's auroral observations. J Space Weather Space Clim 11: 17. https://doi.org/10.1051/swsc/2020082.

Siscoe G, Crooker NU, Clauer CR. 2006. Dst of the Carrington storm of 1859. Adv Space Res 38. https://doi.org/10.1016/j.asr. 2005.02.102.

Stephenson FR, Willis DM, Hallinan TJ. 2004. The earliest datable observation of the aurora borealis. Astron Geophys 45: 6 . https://doi.org/10.1046/j.1468-4004.2003.45615.x.

Suvorova AV, Dmitriev AV, Tsai L-C, Kunitsyn VE, Andreeva ES, Nesterov IA, Lazutin LL. 2013. TEC evidence for near-equatorial energy deposition by $30 \mathrm{keV}$ electrons in the topside ionosphere. $J$ Geophys Res (Space Phys) 118: 4672-4695. https://doi.org/ 10.1002/jgra.50439.

Temmer M, Reis MA, Nikolic L, Hofmeister SJ, Veronig AM. 2017. Preconditioning of interplanetary space due to transient CME disturbances. Astrophys J 835(2): 141. https://doi.org/10.3847/ 1538-4357/835/2/141.

Tverskaya LV, Balashov SV, Vedenkin NN, Ivanov VV, Ivanova TA, et al. 2008. Solar proton increases and dynamics of the electron outer radiation belt during solar events in December 2006. Geomagn Aeron 48: 719-726. https://doi.org/10.1134/ S0016793208060042.

Usoskin IG, Solanki SK, Kovaltsov GA. 2007. Grand minima and maxima of solar activity: new observational constraints. A\&A 471: 301-309. https://doi.org/10.1051/0004-6361:20077704.

Usoskin IG, Solanki SK, Kovaltsov GA. 2011. Grand minima of solar activity during the last millennia, in Comparative Magnetic Minima: Characterizing quiet times in the Sun and Stars. Proc Int Astron Union, IAU Symposium 286: 372-382. https://doi.org/ 10.1017/S174392131200511X.

Vallance Jones A. 1992. Historical review of great auroras. Can J Phys 70: 479-487. https://doi.org/10.1139/p92-083.

Vaquero JM, Valente MA, Trigo RM, Ribeiro P, Gallego MC. 2008. The 1870 space weather event: Geomagnetic and auroral records. $J$ Geophys Res 113: A08230. https://doi.org/10.1029/ 2007JA012943.

Vaquero JM, Vázquez M. 2009. Terrestrial Aurorae and solarterrestrial relations. In: Chap 6 in The sun recorded through history, Astrophysics and Space Science Library, Vaquero JM, Vázquez M (Ed.), Springer, New York, NY, Vol. 361, pp. 279-336. https://doi. org/10.1007/978-0-387-92790-9.

Vázquez M, Vaquero JM, Curto JJ. 2006. On the connection between solar activity and low-latitude aurorae in the period 1715-1860. Sol Phys 238: 405-420. https://doi.org/10.1007/s11207-006-0194-2.

Watari S, Kunitake M, Kitamura K, Hori T, Kikuchi T, et al. 2009. Measurements of geomagnetically induced current in a power grid in Hokkaido, Japan. Space Weather 7: S03002. https://doi.org/ 10.1029/2008SW000417. 
Willis DM, Stephenson FR. 2000. Simultaneous auroral observations described in the historical records of China, Japan and Korea from ancient times to AD 1700. Ann Geophys 18: 1-10. https://doi.org/ 10.1007/s00585-000-0001-6.

Willis DM, Stephenson FR, Singh JR. 1996. Auroral Observations on AD 1770 September 16: the Earliest Known Conjugate Sightings. Q J Roy Astr Soc 37: 733-742. https://www.researchgate.net/publication/234226512_Auroral_Observations_on_AD_ 1770_September_16_the_Earliest_Known_Conjugate_Sightings, accessed on 20 Dec 2020
World Data Center for Geomagnetism, Kyoto M, Nose M, Iyemori T, Sugiura M, Kamei T. 2015. Geomagnetic Dst index. https://doi. org/10.17593/14515-74000.

Zhang W, Zhang DH, Xiao Z. 2009. The influence of geomagnetic storms on the estimation of GPS instrumental biases. Ann Geophys 27(4): 1613-1623. https://www.ann-geophys.net/27/1613/2009/.

Zhou GP, Xiao CJ, Wang JX, Wheatland MS, Zhao H. 2011. A current sheet traced from the Sun to interplanetary space. $A \& A$ 525: A156. https://doi.org/10.1051/0004-6361/201015726.

Cite this article as: Knipp DJ, Bernstein V, Wahl K \& Hayakawa H 2021. Timelines as a tool for learning about space weather storms. J. Space Weather Space Clim. 11, 29. https://doi.org/10.1051/swsc/2021011. 